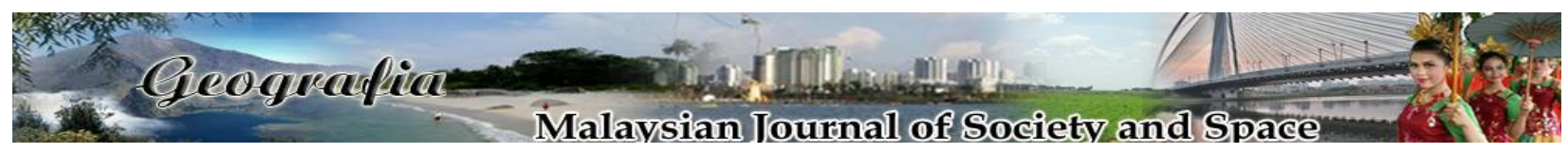

\title{
Perubahan budaya masyarakat Orang Asli Suku Temiar di Kampung Bukit Cermin, Kuala Kangsar, Perak
}

\author{
Mohamad Hakimi Ahmad Khairuddin, Muammar Ghaddafi Hanafiah \\ Pusat Kajian Bahasa, Kesusasteraan dan Kebudayaan Melayu, Fakulti Sains Sosial dan Kemanusiaan, \\ Universiti Kebangsaan Malaysia \\ Correspondence: Muammar Ghaddafi Hanafiah (email: muammar@ukm.edu.my)
}

Received: 04 March 2021; Accepted: 07 May 2021; Published: 29 May 2021

\begin{abstract}
Abstrak
Kajian ini membincangkan budaya terkini masyarakat Orang Asli suku Temiar di Malaysia. Kajian tentang perubahan terkini budaya suku ini boleh dikaji lagi khasnya setelah mereka berpindah ke penempatan baharu di Kg. Bukit Cermin, Kuala Kangsar, Perak. Objektif kajian adalah untuk mengenal pasti budaya suku ini dan menganalisis corak serta faktor perubahan budaya tradisi mereka di situ. Metodologi kajian menggunakan kaedah kualitatif dengan pendekatan etnografi. Kajian lapangan dilakukan dengan melibatkan pemerhatian dan temu bual berfokus bagi memperoleh data utama. Kajian kepustakaan dilakukan untuk menyokong kajian lapangan. Skop budaya yang dikaji adalah kepercayaan, pantang larang dan ritual. Data dianalisis menggunakan teori difusi budaya dan konsep corak perubahan. Hasil kajian mendapati mereka telah meninggalkan kepercayaan animisme dan menganut Islam. Namun, mereka masih lagi mengamalkan pantang larang tradisi leluhur mereka seperti pantang larang masuk hutan, pantang larang mengambil petai dan pantang larang mengambil buluh bagi menjaga keselamatan diri. Mereka juga sering mempersembahkan tarian-tarian warisan leluhur seperti tarian Sewang, tetapi hanya untuk berhibur bukan untuk berubat. Corak perubahan kepercayaan mereka adalah 'reactive change' dan faktornya ialah penyebaran unsur kebudayaan daripada satu masyarakat kepada satu masyarakat yang lain. Corak perubahan pantang larang ialah 'revolutionary change' dan faktornya terdapat inovasi baru yang bermanfaat dan dapat diterima oleh kebudayaan sesebuah masyarakat. Manakala corak perubahan ritual ialah 'total change' dan faktor perubahannya adalah akulturasi budaya. Semuanya adalah natijah daripada proses difusi Islam ke dalam sistem kepercayaan yang mempengaruhi kehidupan dan kebudayaan mereka.
\end{abstract}

Kata kunci: animisme, difusi, pantang larang, perubahan budaya, Temiar, Sewang 


\title{
Cultural change of Orang Asli community of Temiar tribe in Kampung Bukit Cermin, Kuala Kangsar, Perak
}

\begin{abstract}
This study examines the cultural changes of the Temiar tribe in Malaysia. Studies on recent changes in this tribal culture can be continued especially after they make a new settlement in Kampung Bukit Cermin, Kuala Kangsar, Perak. The objective of the research is to identify the cultures of the Temiar and analyse the patterns and factors of change in their traditional cultures. This study is a qualitative study with ethnographic approach. Field studies were conducted involving focused interviews and observations, and supported by library research. The scope of the cultural aspects studied are beliefs, taboos and rituals. Data were analysed using cultural diffusion theory and the pattern of cultural change concept. The results of the study found that the Temiar had abandoned their animistic belief after converted to Islam. However, they still practice the taboo of ancestral traditions for personal safety such as the taboo to enter the forest and collecting petai and bamboos. They also frequently perform ancestral heritage dances such as the Sewang but only for entertainment purposes. The spread of cultural elements from other society has caused a reactive change in their beliefs. There is a pattern of revolutionary change in taboo practices when there is innovation that is beneficial and acceptable to a society's culture. Meanwhile, there was a total change pattern of ritual because of cultural acculturation. The cultural change of this society is the result of the process of Islamic diffusion into the belief system that affects their lives and culture.
\end{abstract}

Keywords: animism, diffusion, taboo, cultural change, Temiar, Sewang

\section{Pengenalan}

Kajian ini merupakan kajian lanjutan dalam perspektif budaya masyarakat peribumi Orang Asli di Semenanjung Malaysia. Menurut Hassan (1998) masyarakat di Malaysia ada dua kategori; Bumiputera dan Orang Asli. Bumiputera merujuk kepada masyarakat peribumi yang tinggal di Sabah dan Sarawak manakala istilah Orang Asli digunakan untuk peribumi yang tinggal di Semenanjung Malaysia. Mereka sehingga hari ini masih golongan minoriti dan mereka bertebaran di seluruh Semenanjung Malaysia kecuali Perlis dan Pulau Pinang (Haliza, 2018).

Terdapat tiga suku kaum utama Orang Asli di Semenanjung Malaysia iaitu Negrito, Senoi, dan Melayu Proto (Jimin, 1968; JAKOA, 2020). Suku Negrito dipercayai telah tiba di Semenanjung Malaysia kira-kira 25000 tahun yang lalu, disusuli orang Senoi sekitar 6000-8000 tahun yang lalu dan suku Melayu Proto sekitar 4000 tahun yang lalu (Hassan, 1998; JAKOA, 2020).

Daripada pemerhatian (2020), didapati mereka masih sangat taat kepada adat dan kepercayaan leluhur mereka. Mereka telah dididik dan diajari sebegitu sejak kecil untuk menghormati dan patuh kepada ketua iaitu Tok Batin ataupun Lembaga Adat. Mereka percaya bahawa pelanggaran pada sesuatu adat akan mendapat balasan 'tulah' daripada tuhan nenek moyang mereka. 
Dewasa ini, banyak perubahan telah berlaku dalam kehidupan mereka. Menurut Devamany, \& Asan (2016) kehidupan mereka bertambah baik daripada sebelumnya. Kerajaan memberi pelbagai insentif dalam pelbagai aspek seperti perumahan, kemudahan asas, jaringan dan perubatan. Insentif berkenaan telah mengubah pelbagai aspek kehidupan mereka. Kehidupan mereka mula mengalami perubahan disebabkan pembangunan yang berlaku ini.

\section{Sorotan literatur}

Bahagian ini menjelaskan tiga bentuk kajian lepas yang menjadi sandaran kajian ini. Kajian-kajian tersebut sama ada berbentuk umum menyentuh masyarakat Orang Asli di Malaysia yang terdiri dari pelbagai suku kaum atau kajian khusus mengenai suku Temiar atau kajian yang menggunakan konsep perubahan budaya dalam menjalankan analisis.

Banyak kajian umum tentang Orang Asli Malaysia yang antaranya turut merangkumi masyarakat suku Temiar seperti dilakukan Alberto G. Gomes (1988) ketika mengkaji Orang Asli Semai. Kajian khusus mengenai suku Temiar pula tidak kurang banyaknya. Kajian-kajian tersebut merangkumi pelbagai aspek seperti kepercayaan, bahasa, budaya material dan pantang larang atau dalam skop kearifan tempatan.

Amir Ahmad et al. (2018) menjalankan kajian etnografi terhadap konsep jiwa dalam kepercayaan masyarakat Temiar. Kajian tersebut menjelaskan beberapa konsep jiwa yang terdapat dalam sistem kepercayaan masyarakat Temiar yang tinggal di kawasan Kuala Mu, Lasah, Sungai Siput, Perak. Kajian tersebut menggunakan kaedah etnografi bagi mengutip data di lapangan. Berdasarkan penemuannya, terdapat tiga konsep jiwa dalam kepercayaan masyarakat Temiar iaitu jiwa manusia dan jiwa bukan manusia yang meliputi flora dan fauna. Perbincangan adalah tentang pandangan masyarakat Temiar terhadap setiap jiwa tersebut dan cara mereka berhubung serta menanggapi konsep jiwa tersebut dalam kehidupan seharian.

Riduan Makhtar et al. (2018) mengkaji bentuk pengaruh dialek Kelantan dalam bahasa Temiar dengan menggunakan analisis fonologi struktural. Kajian tersebut membincangkan pengaruh dialek bahasa Kelantan dalam bahasa Temiar. Kawasan kajian meliputi kawasan perkampungan Orang Asli Temiar di Gua Musang, Kelantan. Data dikumpulkan melalui kaedah temu bual dan rakaman. Hasil analisis mendapati dialek Kelantan telah menyerap ke dalam bahasa Temiar antaranya merangkumi perkara teknologi, binatang, tumbuhan dan pakaian.

Kajian budaya Orang Asli Temiar di Kelantan dibuat oleh Mohd Fahmi Ismail dan Mohd Firdaus Che Yaacob (2018) mengkhusus kepada nilai budaya dalam cerita rakyat masyarakat Orang Asli Temiar Gua Musang, Kelantan sebagai satu sastera warisan. Kajian ini bertujuan untuk memperlihatkan sejauh mana sastera lisan dalam masyarakat Temiar dapat memberi gambaran kepada kebudayaan masyarakat ini. Kajian ini menggunakan sepenuh gagasan yang dikemukakan oleh A. Wahab Ali (2005) iaitu Teori Sastera Warisan. Hasil kajian menjelaskan nilai budaya yang selama ini menjadi landasan kepada ketamadunan masyarakat Orang Asli Temiar di Gua Musang, Kelantan. Sementara itu, elemen nilai budaya yang dihasilkan oleh masyarakat Temiar merupakan manifestasi kehidupan, adat kepercayaan dan lambang jati diri masyarakatnya.

Hamid Muhammad Isa dan Mokthar Saidin (2017) membuat kajian tentang rumah tradisi Temiar dan hubungannya yang simbiosis dengan persekitaran. Kajian ini membincangkan tentang tahap adaptasi dan persekitaran alam memberi pengaruh terhadap ciri sosiobudaya dan corak penempatan sesebuah masyarakat. Kajian ini dilakukan menggunakan kaedah etnografi dan dijalankan di kawasan penempatan suku Temiar di Hulu Kelantan, Hulu Kinta, dan Sungai Siput. 
Hasil kajian mendapati bahawa corak adaptasi di persekitaran hutan hujan tropika memiliki hubungan yang simbiosis dengan corak rumah tradisional masyarakat Temiar. Selain itu, kajian ini membincangkan tentang fungsi ruang dalam reka bentuk rumah mereka. Pada masa itu, kajian mendapati perubahan berlaku secara perlahan-lahan dalam corak penempatan, namun masyarakatnya masih mengekalkan rumah tradisional terutamanya yang tinggal di kawasan pendalaman.

Antara lain lagi ialah dua kajian yang diterbitkan tahun 2014 dalam skop merekayasa kearifan tempatan suku Temiar. Kajian pertama oleh Soijah Likin dan Nazarudin Zainun yang dilakukan di Kampung Semelor, Tasik Banding dan kajian kedua oleh Nurul Nadiah Md.Salleh mengenai skop perayaan suku Temiar dengan mengkaji sewang pantang yang berkait dengan sesuatu kematian dalam kalangan suku Temiar. Lebih awal antaranya Adi Haji Taha (1985) ketika menjelaskan tentang ekskavasi semula batu lindungan di Gua Cha, Ulu Kelantan turut menyentuh suku Temiar.

Terdapat beberapa hasil kajian khusus dan terperinci daripada pengkaji luar tentang suku Temiar di Malaysia dan telah dibukukan khasnya seperti Benjamin (2014) yang membuat penelitian ilmiah mengkhusus kepada kepercayaan animisme suku Temiar dari 1964-2012. Sebelumnya beliau telah mengemukakan beberapa penulisan mengenai suku Temiar pada 1976a, 1968a., 1968b., 1966 dan 1967a., 1967b., 1996, 2011 menyentuh pelbagai skop seperti agama, sosial, kekeluargaan, kepimpinan, linguistik dan tatabahasa Temiar. Beliau umumnya mengkaji banyak hal tentang semua etnik Orang Asli di Semenanjung Tanah Melayu yang turut menjelaskan tentang suku Temiar sebagai salah satu suku Aslian Tengah daripada kategori pembahagian kedua menurut sosiolinguistik (1976b.). Selain itu, John Slimming (1958) mengemukakan sebuah kajian etnologi mengenai pengembaraan di hutan Temiar.

Dalam aspek kajian perubahan budaya, terdapat beberapa penulisan dapat dirujuk seperti kajian budaya tradisi berevolusi seperti rodat dilakukan oleh Muhammad Irfan Nyia Abdullah et al. (2013). Kajian ini adalah tentang persembahan tradisi rodat. Rodat merupakan persembahan yang menggabungkan elemen muzik, tarian dan nyanyian. Kajian ini dilakukan menggunakan kaedah kepustakaan dan kerja lapangan untuk mendapatkan maklumat. Berdasarkan penelitian, terdapat perubahan dalam tradisi persembahan rodat. Selain itu, kajian mendapati kesenian rodat di Kuala Terengganu semakin ditelan zaman. Oleh itu, kesenian rodat mengalami proses evolusi yang dapat dilihat daripada aspek fungsi, kostum, lirik, dan struktur persembahan. Hal ini berlaku disebabkan perubahan zaman tersebut. Faktor anak muda yang enggan mewarisi kesenian rodat merupakan punca kepupusan kesenian rodat di Kuala Terengganu.

Zuriatunfadzilah Sahdan et al. (2009) mengkaji perubahan budaya orang Bateq dalam situasi ekopelancongan di Taman Negara. Objektif kajian tersebut adalah untuk melihat perubahan budaya Orang Asli suku kaum Bateq dari empat aspek iaitu bahasa, pakaian, pemakanan dan kraf tangan. Kajian tersebut disebut menggunakan teori difusi untuk memperlihatkan tahap perubahan budaya yang berlaku dalam kalangan orang Bateq. Namun bentuk teori difusi tidak sampai menjelaskan jenis corak perubahan yang berlaku. Kajiannya memberikan huraian deskriptif terhadap perubahan yang berlaku di samping menyatakan faktor-faktor pendorong kepada perubahan tersebut. Hasil kajiannya mendapati bahawa daripada keempat-empat elemen budaya yang dikajinya, hanya satu daripadanya mengalami perubahan iaitu elemen pakaian. Hal ini dikatakan menunjukkan kepada daya ketahanan budaya orang Bateq yang tinggi. Teori difusi yang digunakan dalam kajian tersebut memfokuskan kepada empat aspek budaya iaitu sepertimana yang telah disebutkan. Namun kajian ini berbeza darinya kerana menumpu kepada difusi dalam tiga 
aspek lain iaitu kepercayaan, pantang larang dan ritual sebagai budaya tradisi yang masih diamalkan oleh suku Temiar di masa kini.

\section{Metodologi kajian}

Kajian ini adalah kajian kualitatif yang berkonsep etnografi melibatkan kajian lapangan dan kajian kepustakaan. Kajian kepustakaan adalah untuk membina latar belakang dan konsep kajian serta menyokong data utama yang diperoleh daripada kajian lapangan. Kaedah kajian lapangan adalah seperti kaedah pemerhatian dan temu bual berfokus. Lokasi kajian adalah di Kampung Bukit Cermin, Kuala Kangsar, Perak untuk mengenal pasti budaya tradisi yang masih diamalkan oleh masyarakat di situ. Melalui pemerhatian dan temu bual dapat dilihat budaya masyarakat di Kampung Bukit Cermin, Kuala Kangsar, Perak. Kaedah temu bual berfokus iaitu secara formal dan tidak formal digunakan bagi mengutip data yang terkini. Temu bual tidak formal diaplikasi kepada golongan muda suku Temiar untuk memastikan suasana santai terbentuk tanpa merasa tekanan dan keterpaksaan serta wujud rasa kemesraan dan keselesaan ketika disapa oleh orang luar lagi tidak dikenali. Keadaan diyakini dapat menghasilkan data yang sesuai lagi benar kerana daripada pemerhatian awal dilihat mereka agak malu dan seperti tidak selesa kerana kurang bercampur dengan masyarakat luar. Temu bual formal pula diaplikasi ketika menemu bual beberapa informan terpilih seperti pegawai di JAKOA yang tersedia untuk sebarang informasi berkaitan, ketua masyarakat di Kampung Bukit Cermin yang mesra dipanggil Tok Batin Omar, seorang guru agama lantikan Jabatan Agama Islam Kuala Kangsar bernama Ustaz Azmi dari suku Temiar di situ, dan seorang gadis kampung suku Temiar yang hanya mahu dikenali sebagai Dayang. Temu bual dijalankan dalam tahun 2020. Data yang diperoleh dihurai secara deskriptif dan dianalisis menggunakan Teori Perubahan Budaya dan konsep Perubahan.

\section{Teori kajian}

Data kajian yang diperoleh daripada kajian lapangan disusun menurut tiga skop iaitu kepercayaan, pantang larang dan ritual. Untuk menganalisis perubahan budaya masyarakat padanya, kandungan data tersebut akan diterangkan maksudnya sebelum dianalisis menggunakan Teori Perubahan Budaya dan konsep Perubahan. Kedua-dua teori dan konsep ini akan melengkapi satu sama lain. Teori perubahan budaya dapat menjelaskan bentuk perubahan sementara konsep perubahan dapat menjelaskan arah atau corak perubahan dan faktor-faktornya. Pada dasarnya Teori Perubahan Budaya dibahagikan kepada dua teori lain iaitu Teori Evolusi (Universal dan Multilinear) dan Teori Difusi. Kajian ini menumpu kepada perspektif difusi dengan mencari faktor-faktor perubahan kepercayaan, pantang larang dan ritual. Hal ini adalah demikian kerana dilihat masyarakat Orang Asli suku Temiar di penempatan baharu mereka iaitu Kg. Bukit Cermin telah meninggalkan kepercayaan tradisi nenek moyang mereka dengan menerima Islam. Sementara untuk menganalisis corak perubahan dan faktornya, kajian ini menggunakan konsep-konsep perubahan antaranya seperti Happened Change, Planned Change, Total Change, Reactive Change, Transformational Change, Revolutionary Change dan Strategic Change (K. Harigopal, 2006). Hal ini demikian adalah kerana konsep-konsep perubahan ini diyakini dapat menjelaskan arah atau corak perubahan dengan lebih ilmiah dan berkesan. Jadual di bawah menjelaskan secara ringkas corak-corak konsep perubahan budaya yang digunakan dalam kajian ini. 
Jadual 1. Jenis corak perubahan.

\begin{tabular}{cll}
\hline No & Corak Perubahan & \multicolumn{1}{c}{ Maksud } \\
\hline 1. & Happened Change & $\begin{array}{l}\text { Perubahan yang tidak dapat diramalkan, berlaku secara semula jadi } \\
\text { disebabkan faktor luaran }\end{array}$ \\
2. & Planned Change & $\begin{array}{l}\text { Perubahan terancang sebagai tindak balas terhadap tuntutan dalaman } \\
\text { dan luaran, biasanya berlaku dalam aspek matematik. }\end{array}$ \\
3. & Total Change & $\begin{array}{l}\text { Perubahan drastik daripada sistem yang sedia ada } \\
\text { Perubahan daripada tindak balas daripada sesuatu peristiwa atau } \\
\text { rangkaian peristiwa. }\end{array}$ \\
4. & Reactive Change & $\begin{array}{l}\text { Perubahan yang melibatkan semua atau sebahagian besar organisasi } \\
\text { disebabkan oleh ancaman. }\end{array}$ \\
5. & Transformational & Perubahan mendadak dalam strategik dan reka bentuk organisasi \\
6. & Revolutionary Change & Peraban \\
7. & Strategic Change & Perubahan dalam semua atau sebahagian besar komponen organisasi. \\
\hline
\end{tabular}

Sumber: Kajian lapangan (2020)

\section{Suku Temiar Kampung Bukit Cermin}

Populasi suku Temiar di Malaysia dianggarkan 30,118 orang pada tahun 2010 (Kirk, 2015). Namun mereka yang tinggal di Kampung Bukit Cermin, Kuala Kangsar hanyalah sebilangan kecil yang dianggarkan lebih 200 orang dengan bilangan rumah sebanyak lebih kurang 30 buah (Koknis, 2016).

Penempatan baharu mereka di Kampung Bukit Cermin adalah terletak di kawasan pendalaman di dalam daerah Kuala Kangsar, Perak iaitu kira-kira 20 kilometer dari Bandar Kuala Kangsar. Kawasan ini terletak di antara sempadan Mukim Sayung dan Mukim Senggang (rajah 1). Kampung ini dan sebuah lagi iaitu di Kuala Kangsar iaitu Kampung Ulu Bekor adalah dua buah kampung Orang Asli yang dilaporkan mendapat bantuan kerajaan lebih Ringgit Malaysia 1 juta untuk proses menaiktarafkannya (mStar, 2016).

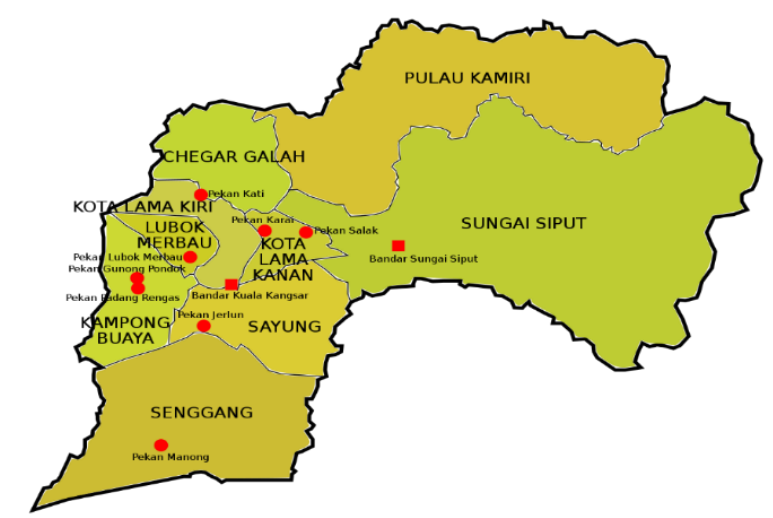

Sumber: Wikiwand.ensiklopedia bebas (t.th.)

Rajah 1. Peta Daerah Kuala Kangsar.

Suku Temiar adalah suku kaum Orang Asli daripada rumpun Senoi. Mereka dipercayai mempunyai pertalian dengan Sri Langka dan India selain ada pendapat mengatakan mereka berasal dari Indochina (Ensiklopedia Sejarah dan Kebudayaan Melayu, 1999, 4: 2454) Suku Senoi terdiri daripada 6 suku iaitu Temiar, Semai, Semaq Beri, Jahut, Mah Meri dan Cheng Wong. Kawasan tempat tinggal mereka adalah di kawasan lereng Banjaran Titiwangsa iaitu di pendalaman Perak, 
Kelantan dan Pahang. Kesemua suku Senoi mempunyai ciri-ciri yang serupa dalam aspek kehidupan seperti gaya hidup dan budaya. (JAKOA, 2020).

Orang lelaki suku Temiar mempunyai warna kulit 'sawo mateng' sementara warna kulit kebanyakan kaum wanita mereka putih atau 'kuning langsat'. Daripada pemerhatian (2020) dilihat dalam kalangan kaum wanita mereka ada yang sudah mengenakan tudung di kepala. Hal ini adalah kerana pengaruh daripada ajaran-ajaran agama Islam yang mereka budayakan.

Selain itu, Daripada pemerhatian (2020) segi gaya pakaian mereka tidak sangat berbeza daripada gaya pakaian masyarakat-masyarakat di luar kampung mahupun di bandar. Ini mungkin kerana kawasan Kampung Bukit Cermin tidak jauh dengan bandar yang membuatkan mereka tidak ketinggalan dari sudut ini. Faktor jaringan pengangkutan darat ke Kampung Bukit Cermin yang baik memudahkan mereka untuk keluar masuk ke kampung serta dapat menghubungkan mereka dengan orang luar khasnya yang datang dari bandar.

Suku Temiar di Kampung Bukit Cermin mencari sumber mata pencarian mereka berdasarkan beberapa sumber. Mereka masih mencari rezeki melalui pengumpulan hasil hutan seperti mencari rotan, petai, gaharu, madu, dan kraf tangan. Selain itu, terdapat sebahagian ahli masyarakat suku Temiar yang sudah bekerja di kilang-kilang dan di syarikat swasta terutama golongan muda.

Menurut Jabatan Kemajuan Orang Asli daerah Kuala Kangsar, kampung Orang Asli di Bukit Cermin adalah di bawah tanggungjawab mereka (JAKOA: 2020). Segala urusan seperti pendaftaran dan kesihatan orang Temiar akan dibuat di jabatan ini. Di kawasan mukim Senggang, Kuala Kangsar, terdapat satu sahaja kampung Orang Asli suku Temiar di situ manakala dua buah kampung Orang Asli lagi berada di Ulu Bekor dan Ulu Perah adalah perkampungan Orang Asli suku Semai.

\section{Perubahan budaya suku Temiar Kampung Bukit Cermin}

Perbincangan ini merujuk kepada perubahan terkini yang berlaku dalam aspek kepercayaan, pantang larang dan ritual masyarakat ini.

\section{Kepercayaan}

Kepercayaan animisme dalam masyarakat Orang Asli sudah sebati dalam budaya kehidupan mereka. Pandang hidup mereka banyak dipengaruhi alam semula jadi membuatkan kepercayaan ini sebati dalam hidup mereka. Setelah Tanah Melayu mencapai kemerdekaan pada tahun 1957 gerakan dakwah dari pelbagai agama giat dijalankan terhadap masyarakat Orang Asli di Malaysia. Agama Islam dan Kristian antara agama yang banyak disebarkan dalam masyarakat Orang Asli di Malaysia. Berdasarkan temu bual dengan pegawai JAKOA (2020) majoriti penduduk Orang Asli suku Temiar di kawasan tersebut telah memeluk agama Islam. Mereka lama menerima ajaran agama Islam. Secara lahiriahnya aspek kehidupan masyarakat Temiar di situ mempunyai persamaan dengan masyarakat Melayu. Namun terdapat beberapa aspek budaya yang masih mempunyai pengaruh kepercayaan animisme yang lama.

Berdasarkan maklumat terkini bahawa penduduk di situ sudah mengamalkan gaya hidup sebagai Muslim. Bahkan ada di antara mereka yang telah dilantik oleh Jabatan Agama Islam daerah Kuala Kangsar menjadi guru agama untuk mengajar berkenaan hal ehwal Islam. Menurut Ustaz Azmi (2020): 
"Masyarakat Orang Asli di kampung ini semuanya dah masuk Islam. Tok Batin kami di sini juga orang Islam. Saya belajar pasal Islam sejak sekolah lagi kemudian saya belajar lagi melalui ustaz-ustaz yang datang ke kampung kami buat ceramah agama di surau."

Kenyataan di atas membuktikan masyarakat ini sudah menerima ajaran Islam sejak di bangku sekolah lagi. Kemudian tahap pengetahuan Islam mereka ditambah dengan gerakan dakwah yang dibuat oleh Jabatan Agama Islam daerah Kuala Kangsar yang sering berkunjung ke kampung tersebut untuk menyampaikan ajaran Islam.

Selain itu, dilihat generasi tua yang berada di situ telah Islam sejak kecil lagi. Hal ini membuktikan datuk nenek mereka telah memeluk Islam lebih awal. Maka tidak hairanlah masyarakat ini sekarang merupakan masyarakat Orang Asli beragama Islam secara majoritinya.

Seterusnya, dilihat sebuah surau dibina di kampung ini (Rajah 2). Daripada maklumat temu bual, ia dibina daripada sumbangan Syarikat PLUS Malaysia Berhad.

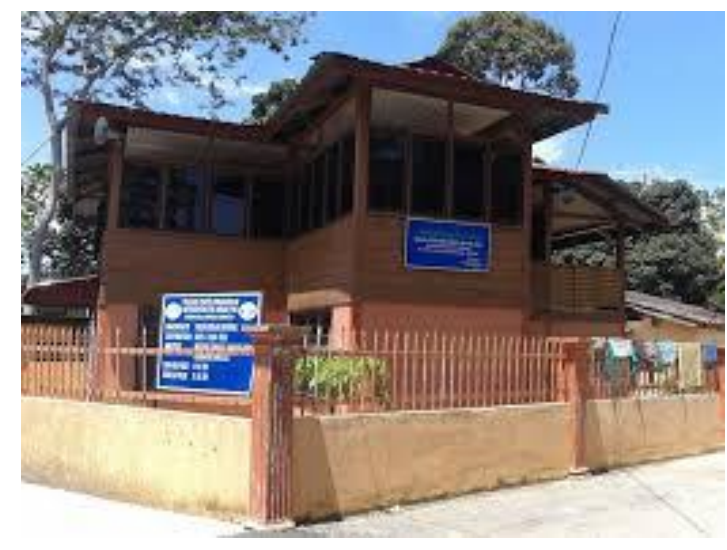

Sumber: Kajian lapangan (2020)

Rajah 2. Surau perkampungan Orang Asli Kampung Bukit Cermin, Sayong, Kuala Kangsar, Perak.

Surau ini dibina untuk menggalakkan masyarakat di situ solat berjemaah dan melakukan aktiviti keagamaan Islam seperi menguruskan jenazah, kenduri tahlil, mengadakan kelas mengaji al-Quran al-Karim dan lain-lain aktiviti komuniti di sini. Surau ini boleh menampung kira-kira 3060 jemaah lelaki dan perempuan. Surau ini juga digunakan sebagai tempat program bersama anakanak Orang Asli suku Temiar (Ustaz Azmi, 2020). Berdasarkan rajah 3, dapat dilihat suasana program bersama anak-anak Orang Asli di Kampung Bukit Cermin. Jelaslah bahawa surau yang dibina berfungsi sebagai tempat beribadat dan melakukan aktiviti yang melibatkan penduduk kampung di situ.

Sepanjang pemerhatian (2020) di situ, didapati masyarakat ini mengamalkan gaya hidup sebagai seorang Muslim. Mereka dilihat belajar fardu ain dan fardu kifayah yang dasar akidahnya adalah Islam sebagaimana yang ada pada masyarakat Melayu. Perubahan budaya dalam aspek kepercayaan tradisi suku Temiar iaitu animisme berlaku apabila majoriti masyarakatnya sudah menerima dakwah Islam. Kini, mereka sudah berpendidikan Islam dan mampu mengamalkan gaya hidup sebagai Muslim yang sebenar. 


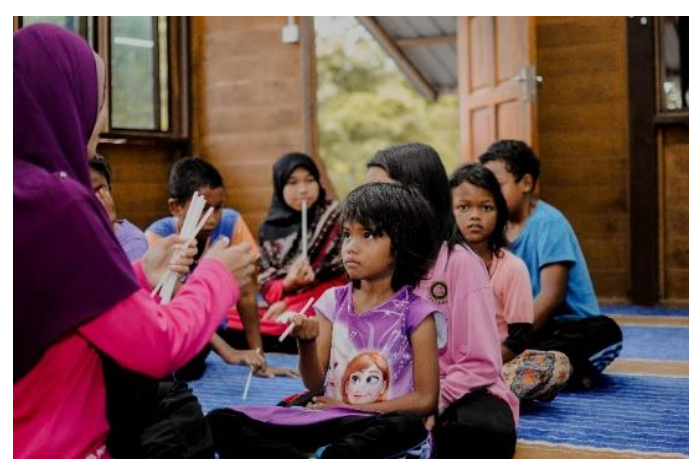

Sumber: Kajian lapangan (2020)

Rajah 3. Suasana di dalam surau perkampungan Orang Asli Kampung Bukit Cermin.

Bagi perubahan budaya dalam aspek kepercayaan, berdasarkan konsep perubahan didapati corak perubahannya adalah 'reactive change' yang berkonsepkan perubahan daripada tindak balas daripada sesuatu peristiwa atau rangkaian peristiwa. Dari sudut pendifusian Islam, dilihat faktor perubahan bagi kepercayaan mereka memperlihatkan penyebaran unsur kebudayaan daripada satu masyarakat kepada satu masyarakat yang lain. Islam berdifusi dalam keseluruhan sistem kepercayaan masyarakat ini. Sistem kepercayaan Islam yang membentuk jati diri masyarakat Islam telah membentuk falsafah tentang pegangan dan pandang hidup baharu mereka. Ia bersifat menyeluruh lagi meliputi mencakupi seluruh cabang kehidupan duniawi yang sementara hingga kepada kehidupan kekal abadi di akhirat.

\section{Pantang Larang}

Beberapa pantang larang diamalkan oleh mereka sewaktu hendak masuk ke dalam hutan bagi mencari dan mengumpulkan hasil hutan. Menurut Tok Batin Omar:

"Orang Temiar di sini masih mengamalkan pantang larang daripada leluhur mereka. Sebabnya adalah setiap pantang larang itu mempunyai kepentingan tersendiri supaya dapat menjaga keselamatan anak cucu ketika berada di hutan untuk memburu atau mencari rezeki” (Tok Batin Omar, 2020).

Kenyataan di atas menjelaskan kepentingan dalam mematuhi pantang larang yang diciptakan oleh leluhur mereka. Walaupun mereka tidak tahu akan kewujudan pantang larang tersebut namun mereka tetap akan mematuhi kerana mereka percaya bahawa setiap pantang larang itu dibuat atau dicipta bertujuan untuk menjaga keamanan dan selamat suku kaum mereka. Pantang larang yang masih diamalkan dilihat telah dimoderatkan dengan menyesuaikannya dengan tuntutan dan larangan Islam dalam kehidupan mereka. Maka sesuai dengan maksud moderat itu sendiri iaitu tidak keterlaluan dengan membuang terus budaya ini daripada kehidupan lalu dikekalkan dengan corak lebih sederhana dan harmonis. 
a. Pantang larang masuk hutan

Didapati mereka masih mempraktikkan pantang larang ketika berada di dalam hutan. Hal ini adalah kerana pantang larang mereka merangkumi keseluruhan pola kehidupan mereka. Tok Batin Omar mengatakan:

"Pantang larang perkara yang penting dalam kehidupan Orang Asli. Kehidupan kami di hutan wajib mengikut pantang larang supaya tidak berlaku perkara-perkara yang tidak diingini atau kemalangan. Perkara paling penting ketika masuk ke hutan adalah kita perlu menjaga mulut daripada berkata-kata benda yang tidak baik" (Tok Batin Omar, 2020).

Menjaga mulut di atas bermaksud larangan dari berkata-kata tentang perkara-perkara yang tidak elok seperti menyebut harimau atau jembalang. Hal ini adalah kerana dikhuatiri kata-kata atau niat yang tidak baik itu akan mengundang sesuatu yang tidak baik seperti disampuk hantu atau terserempak dengan binatang liar. Cara ini dapat mengawal dan membersihkan fikiran dan jiwa dari prasangka yang buruk serta dapat memusatkan perhatian kepada pekerjaan.

\section{b. Pantang larang mengambil petai}

Masyarakat Temiar terkenal mahir memetik petai hutan yang tumbuh dengan banyak di kawasan mereka. Petai hutan mempunyai rasa yang istimewa. Mereka gemar memungut petai hutan untuk dibuat makan dan dijual. Namun terdapat pantang larang dari leluhur mereka jika ingin mengambil petai. Mereka dilarang untuk memotong dahan petai dan menebang pokok. Selain itu, mereka juga dilarang daripada mengambil petai yang belum matang. Mereka perlu menggunakan galah yang diperbuat daripada buluh untuk mengait petai. Sekiranya pokok petai tersebut tinggi dan besar, mereka akan menggunakan 'sigai' iaitu tali yang diikat pada dahan pokok dan mereka akan mengait petai-petai dari atas pokok.

Ternyata seperti terdapat hikmah di sebalik semua langkah dan petua yang dilakukan di atas. Walaupun dikira asalnya mungkin daripada pengalaman dan tanggapan animisme leluhur mereka terdahulu namun kini semuanya dipercayai mengandungi kebaikan untuk menjaga keselamatan diri semasa di hutan dan untuk menjaga nikmat alam flora dan fauna daripada kerosakan. Hal ini terus dibudayakan dan ditradisikan daripada generasi kepada generasi. Ia seakan satu seni kehidupan dan tatacara terhadap kejadian-kejadian alam daripada ciptaan tuhan yang tidak lagi dikaitkan dengan animisme.

Kalau mengambil petai yang belum matang tentu adalah tidak berfaedah dan membazirkan hasil hutan. Jika menggunakan buluh dan sigai untuk memanjat dan mengait petai tentu untuk tujuan menjaga batang, dahan dan ranting pokok petai hutan daripada kerosakan yang mengakibatkan kepupusan akibat ditebuk paku dan dikelar atau ditakik.

\section{c. Pantang larang mengambil rotan}

Untuk mengambil hasil hutan seperti rotan, orang Temiar perlu berpengetahuan dan bersedia mengikuti pantang larang yang diwariskan dari leluhur mereka. Hasil rotan mudah diperoleh oleh mereka di hutan belukar. Pekerjaan mencari rotan sudah sebati dengan mereka kerana ia adalah aktiviti wajib suku mereka. Orang Temiar dikenali hanya akan menjual rotan yang terjamin kualiti 
dan memiliki ketahanan. Rotan mereka biasanya dibeli oleh orang Cina. Ada juga rotan-rotan yang dianyam dan sebagainya menjadi hasil kraf tangan yang menarik seperti bakul untuk dipakai dan dijual.

Mereka hanya akan mengambil rotan yang liar sahaja. Hal ini demikian adalah kerana rotan liar memiliki daya ketahanan dan kualiti atau mutu yang tinggi. Rotan yang ditanam sendiri dipercayai tidak mempunyai kualiti dan mudah patah. Bagi masyarakat Temiar mereka harus mencari rotan yang berkualiti sahaja. Mereka pantang menjual rotan yang tidak mempunyai kualiti kepada orang. Ini adalah kerana antara tujuan dicipta pantang larang adalah untuk membentuk keperibadian yang luhur seperti jujur dalam berniaga. Dapat ditafsirkan ia juga untuk menjaga nama baik atau maruah mereka.

Bagi masyarakat ini, pantang larang merupakan sebahagian daripada kehidupan mereka. Ini bermakna pantang larang adalah sebahagian daripada budaya masyarakat ini. Pantang larang juga berfungsi sebagai alat kawalan terhadap masyarakat mereka. Setiap pantang larang yang dicipta mempunyai nilai tersendiri untuk mendidik masyarakat ini supaya menghormati alam semula jadi yang banyak memberi manfaat kepada kehidupan mereka.

Pantang larang leluhur mereka dahulu telah mengalami perubahan kepada bersifat lebih moderat. Pantang larang moderat ini tidak lagi merujuk unsur-unsur animisme yang wujud bersama pantang larang leluhur yang asal yang dikaitkan dengan 'ruai'(roh), hantu, jembalang, penunggu, harimau, bukit, petir, pokok dan seumpamanya tetapi diubahsuai dan hanya diamalkan oleh mereka dengan maksud menjaga keselamatan diri dan nyawa sahaja. Kemungkinan ia menjadi seperti petua lama yang masih berguna kerana berdasarkan pengalaman hidup orang tuatua sahaja.

Bagi perubahan budaya dalam aspek pantang larang, berdasarkan konsep perubahan didapati corak perubahannya adalah 'revolutionary change' yang berkonsepkan perubahan mendadak dalam strategik dan reka bentuk. Faktor perubahan bagi pantang larang adalah berdasarkan kepada terdapatnya penemuan/inovasi baharu yang bermanfaat dan dapat diterima dalam kebudayaan sesebuah masyarakat. Maka pantang larang leluhur mereka yang diasaskan di atas kepercayaan animisme dan pengalaman berinteraksi dengan hutan pada zaman dahulu telah dimoderatkan dengan hanya menerima apa yang bermanfaat untuk diamalkan daripada sisi yang tidak bertentangan dengan ajaran Islam seperti pantang larang yang diperuntukkan untuk menjaga keselamatan diri semasa berada di hutan. Falsafah Islam mengajar kepada menerima konsep ikhtiar dan asbab serta sentiasa akur dengan takdir Allah yang Maha Berkuasa.

\section{Ritual}

Antara ritual yang masih dibudayakan oleh suku Temiar ialah tarian sewang. Menurut Norlida Mohd, \& Mohd Hassan (2020), ritual 'sewang' mempunyai dua fungsi iaitu bertujuan untuk perubatan mengubati penyakit, menyambut kelahiran bayi, meneroka ladang baharu, membersihkan kampung yang dilanda bencana dan sebagai tanda bersyukur.

Daripada pemerhatian dan temu bual yang dijalankan, sewang di masa kini adalah untuk sekadar persembahan bagi mengelakkan budaya warisan ini pupus ditelan zaman. Kenyataan ini dapat dijelaskan oleh seorang penduduk kampung bernama Dayang:

"Tarian sewang di kampung ini jarang dilakukan. Kalau ada pun bila ada orang luar datang melawat kampung. Sewang di sini tidak gunakan jampi serapah. Hanya sekadar hiburan untuk orang luar yang datang" (Dayang, 2020). 
Sewang untuk persembahan ini dilakukan untuk majlis-majlis tertentu sahaja seperti menyambut tetamu, menyambut kesyukuran, dan hiburan semata-mata. Terdapat beberapa unsur yang masih dikekalkan dan dibuang dalam seni tarian tersebut. Jampi dan serapah telah dibuang kerana dibimbangkan mengandungi unsur syirik. Hanya penggunaan alat muzik dan penari wanita yang masih dikekalkan dalam menjayakan persembahan.

Alat muzik yang wajib ada dalam tarian sewang adalah gendang, gong, dan centung. Semua alat muzik tersebut masih dikekalkan dalam tarian Sewang persembahan yang dijalankan. Penari wanita pula merupakan elemen yang penting dalam Tarian Sewang Persembahan ini. Sebanyak 10 orang penari wanita yang diperlukan dalam satu persembahan sewang. Mereka menari mengikut gerak-geri tertentu yang telah ditetapkan oleh ketua persembahan. Bagaimanapun tarian sewang ini hanya akan dibuat apabila ada tetamu dari luar datang melawat kampung seperti wakil rakyat. Persembahan atau upacara ritual tradisi ini tidak lagi berfungsi sebagai ritual perubatan tetapi sebagai persembahan hiburan atau sebagai pertunjukan kebudayaan dan kesenian.

Bagi perubahan budaya dalam aspek ritual, berdasarkan konsep perubahan, didapati corak perubahannya adalah 'total change' yang berkonsepkan perubahan drastik daripada sistem yang sedia ada. Faktor perubahan bagi ritual adalah berkonsepkan adalah akulturasi budaya. Sewang perubatan telah diubah kepada sewang hiburan dan kebudayaan. Unsur syirik seperti memohon kelegaan dan kesembuhan dari selain Allah telah ditinggalkan akibat akulturasi budaya Islam ke dalam budaya Temiar sepertimana berlaku kepada budaya-budaya masyarakat lain yang menerima Islam seperti Melayu.

Jadual 2 menunjukkan perubahan budaya dalam aspek kepercayaan, pantang larang dan ritual seperti dinyatakan berikut:

Jadual 2. Perubahan budaya suku Temiar.

\begin{tabular}{lll}
\hline Budaya & Dahulu & Terkini \\
\hline Kepercayaan & Animisme & Agama Islam \\
Pantang Larang & Pantang larang leluhur & Pantang larang moderat \\
Ritual & Sewang Perubatan & Sewang Persembahan \\
\hline
\end{tabular}

Sumber: Kajian lapangan (2020)

Jadual 3, data disusun mengikut konsep corak perubahan dan faktor perubahan seperti yang dibincangkan berikut:

Jadual 3. Analisis corak dan faktor perubahan budaya

\begin{tabular}{|c|c|c|}
\hline Budaya & Corak & Faktor \\
\hline Kepercayaan & Reactive Change & $\begin{array}{l}\text { - Difusi Islam dalam sistem kepercayaan. } \\
\text { - Islam membentuk pegangan dan pandang hidup baharu. }\end{array}$ \\
\hline Pantang Larang & Revolutionary Change & $\begin{array}{l}\text { - Difusi Islam dalam pantang larang leluhur dengan } \\
\text { dimoderatkan. . } \\
\text { - Asas baharu adalah konsep ikhtiar, asbab dan takdir Allah. }\end{array}$ \\
\hline Ritual & Total change & $\begin{array}{l}\text { - Difusi Islam dalam Sewang perubatan dengan diubah } \\
\text { kepada sewang hiburan dan kebudayaan. } \\
\text { - Unsur syirik dinyahkan. }\end{array}$ \\
\hline
\end{tabular}

Sumber: Kajian lapangan (2020) 


\section{Kesimpulan}

Perubahan budaya Orang Asli suku Temiar di Kampung Bukit Cermin, Sayong, Kuala Kangsar, Perak berlaku dengan cara yang amat harmonis. Ia adalah disebabkan oleh faktor difusi Islam yang memacu perubahan dinamik sepertimana pernah dikatakan sebelumnya kepada kebudayaan Melayu Islam. Faktor utama kepada segala perubahan ini adalah perubahan sistem kepercayaan Orang Asli suku Temiar sendiri kepada Islam yang dapat dikatakan masih baharu diterima sebagai agama kepercayaan dan cara hidup yang menyeluruh.

Secara spesifik perubahan kepercayaan mereka bercorak 'reactive change' dan faktor difusi Islam padanya ialah kerana penyebaran unsur kebudayaan (Islam) daripada satu masyarakat (Islam) kepada satu masyarakat yang lain (Temiar). Perubahan pantang larang mereka pula adalah bercorak 'revolutionary change' dan faktor difusi Islamnya padanya ialah kerana terdapat inovasi baru (pantang larang yang dimoderatkan) yang bermanfaat dan dapat diterima oleh kebudayaan sesebuah masyarakat (Islam). Sementara perubahan ritual Orang Asli suku Temiar adalah bercorak 'total change' dan faktor difusi Islam dalam perubahannya adalah dari kerana akulturasi budaya Islam ke dalam budaya Temiar.

\section{Penghargaan}

Informan-informan kajian terdiri daripada pegawai informasi di JAKOA, Tok Batin Omar, ketua masyarakat Orang Asli suku Temiar Kampung Bukit Cermin, Kuala Kangsar, Dayang, gadis kampung keturunan Temiar dan Ustaz Azmi, guru agama keturunan Temiar yang bertauliah.

\section{Rujukan}

A. Wahab Ali. (2005). Teori sastera warisan. Dlm. Seminar teori dan kritikan sastera Melayu serantau. Kuala Lumpur, Universiti Malaya.

Adi Haji Taha. (1985). The re-excavation of the rockshelter of Gua Cha, Ulu Kelantan, West Malaysia. Federation Museums Journal, 30, 1-134.

Alberto G. Gomes. (1988). The Semai: the making of an ethnic group in Malaysia. Dlm. A. Terry Rambo, Kathleen Gillogly, \& Karl L.Hutterer (pnyt.). Ethnic diversity and the control of natural resources in Southeast Asia, Honolulu, University of Mechigan Center for South and Southeast Asian Studies.

Amir Ahmad, Hamid Mohd Isa, \& Mokhtar Saidin. (2018). Kajian etnografi terhadap konsep jiwa dalam kepercayaan masyarakat Temiar. Jurnal Arkeologi Malaysia, 31(2), 85-102.

Benjamin, Geoffrey. (1966). Temiar social groupings. Federation Museums Journal, 11, 1-25.

Benjamin, Geoffrey. (1967a.). Temiar religion,. UK, Cambridge Unuversity. PhD thesis.

Benjamin, Geoffrey. (1967b.). Temiar kinship. Federation Museums Journal, 12, 1-25.

Benjamin, Geoffrey. (1968). Headmanship and leadership in Temiar society. Federation Museums Journal, 13, 1-43.

Benjamin, Geoffrey. (1968). Temiar personal names. Bijdragen Tot de Taal-, Land- en Volkenkunde, 124, 99-134.

Benjamin, Geoffrey. (1976a.). An outline of Temiar grammar. Austroasiatic Studies, Part I, 129187. 
Benjamin, Geoffrey. (1976b.). Austroasiatic subgrouping and prehistory in the Malay Peninsula. In Philip N. Jenner, Laurence C. Thompson, Stanley Starosta (Eds.), Austroasiatic Studies Part I (pp. 37-128). University Press of Hawaii,

Benjamin, Geoffrey. (1996). Rationalisation and re-enchantment in Malaysia: Temiar religion, 1964-1995. Department of Sociology Working Papers 130.

Benjamin, Geoffrey. (2011). Deponent verbs and middle-voice nouns in Temiar. In Sophana Srichampa, \& Paul Sidwell (Eds.), Austroasiatic Studies: papers from ICAAL4. MonKhmer Studies Journal Special Issue No. 2. Dallas, SIL International; Salaya, Mahidol University; Canberra, Pacific Linguistics, 11-37.

Benjamin, Geoffrey. (2014). Temiar religion, 1964-2012 enchantment, disenchantment and reenchantment in Malaysia's uplands. Singapore, Nus Press.

Devamany S. Krishnasamy, \& Asan Ali Golam Hassan. (2016). Masyarakat Orang Asli impak program penempatan semula. Sintok, Penerbit UUM.

Ensiklopedia sejarah dan kebudayaan Melayu. (1999). Jilid 4. Edisi Pertama. Cetakan Kedua. Kuala Lumpur, Dewan Bahasa dan Pustaka.

Haliza Abdul Rahman. (2018). World view masyarakat orang asli dan pelestarian alam sekitar. Prosiding Seminar Antarabangsa Arkeologi, Sejarah, Bahasa dan Budaya di Alam Melayu (ASBAM) Ke-7, 28-29 Julai 2018, Hotel Jayakarta Lombok, Nusa Tenggara, Indonesia.

Hamid Muhammad Isa, \& Mokthar Saidin. (2017). Rumah tradisi Temiar dan hubungannya yang simbiosis dengan persekitaran. Jurnal Arkeologi Malaysia. 30(2), 29-38.

Hassan Mat Nor. (1998). Warga peribumi menghadapi cabaran pembangunan. Kertas kadangkala Bil. 8. Jabatan Antropologi, \& Sosiologi. Bangi, Universiti Kebangsaan Malaysia.

Jabatan Kemajuan Orang Asli. (2020). Portal Rasmi Jabatan Kemajuan Orang Asli. (Kementerian Pembangunan Luar Bandar). Retrieved from www.jakoa.gov.my.

Jimin Idris. (1968). Distribution of Orang Asli in West Malaysia. JMBRAS, 7, 45-8.

John Slimming. (1958). Temiar jungle: a Malayan journey. J. Murray. Travel Book Club.

K. Harigopal. (2006). Management of organizational change, leveraging transformation. India, SAGE Publications.

Kirk, Endicott. (2015). Malaysia's original people: Past, present and future of the Orang Asli. t.tp., NUS Press.

Koknis Membebel. (2016). Moh travel ke kampung Orang Asli Bukit Cermin. Retrieved from http://nuranisnadia.blogspot.com/2016/03/moh-travel-ke-kampung-orang-asli-bukit.html

Mohd Fahmi Ismail, \& Mohd Firdaus Che Yaacob. (2018). Nilai budaya dalam cerita rakyat masyarakat Orang Asli Temiar Gua Musang, Kelantan: satu pengaplikasian sastera warisan. International Journal of Creative Future \& Heritage (IJCFH), 6(2), 101-120.

mStar.urban.versatil. (2016). https://www.mstar.com.my/lokal/semasa/2016/06/14/naik-tarafdua-kpg-orang-asli.

Muhammad Irfan Nyia Abdullah, Sakinah Abu Bakar, \& Tasnim Mohd Anuar. (2013). Rodat: budaya tradisi yang berevolusi. Wacana Seni Journal of Arts Discourse, 12.

Norlida Mohd Jalaludin, \& Mohd Hassan Abdullah. (2020). Perubahan dalam Ritual Siwang Kumpulan Bah Lut, Kampung Bukit Terang, Kampar, Perak. Jurnal Kemanusiaan, 27(1), 25-43.

Nurul Nadiah Md. Salleh. (2014). Perayaan kaum Temiar: sewang pantang. Dlm. Nazarudin Zainun, \& Darlina Md. Naim (pnyt.). Merekayasa kearifan tempatan budaya, pelancongan, arkeologi dan sejarah. Pulau Pinang, Penerbit Universiti Sains Malaysia. 
Riduan Makhtar, Soflee, Nurliyana S.M., Mohd Sharifudin Yusop, \& Abd Ganing Laengkang. (2018). International Journal of Education, Psychology and Counseling, 3(11), 42-54.

Soijah Likin, \& Nazarudin Zainun. (2014). Merekayasa kearifan tempatan sebagai mekanisme kawalan sosial: kajian kes suku Temiar Kampung Semelor, Tasik Banding. Dlm. Nazarudin Zainun, \& Darlina Md. Naim (pnyt). Merekayasa kearifan tempatan budaya, pelancongan, arkeologi dan sejarah. Pulau Pinang, Penerbit Universiti Sains Malaysia.

Wikiwand.ensiklopedia bebas. (t.th.). Daerah Kuala Kangsar. https://www.wikiwand. com/ms/Daerah_Kuala_Kangsar.

Zuriatunfadzilah Sahdan, Rosniza Aznie Che Rose, \& Habibah Ahmad. (2009). Perubahan budaya orang Bateq dalam situasi ekopelancongan di Taman Negara. e-Bangi Journal of Social Sciences and Humanities, 4(1), 159-169, 2009. 